\section{REVIEW} ARTICLE

\title{
Glucose control in Saccharomyces cerevisiae: the role of MIG1 in metabolic functions
}

\author{
Christopher J. L. Klein, Lisbeth Olsson and Jens Nielsen \\ Author for correspondence: Lisbeth Olsson. Tel: +45 45 252 684. Fax: +4545884148. \\ e-mail: LO@ibt.dtu.dk
}

Center for Process Biotechnology, Department of Biotechnology, Building 223, Technical University of Denmark, DK-2800 Lyngby, Denmark

Keywords: Saccharomyces cerevisiae, glucose repression, MIG1, peripheral and central metabolism, genetic engineering

\section{Overview}

Industrial cultivation media, such as molasses, wort, agricultural waste and lignocellulose hydrolysates, contain a mixture of metabolizable carbohydrates. These carbohydrates are taken up by cells in a certain order with intermittent lag phases due to a set of mechanisms controlled by glucose, referred to hereafter as glucose control. Thus, the presence or uptake of glucose has a negative impact upon the metabolism of other sugars. Glucose repression reduces the transcription rate of repressible genes, and is the most thoroughly investigated mechanism of glucose control (Fig. 1).

In this review the different mechanisms of glucose control in Saccharomyces cerevisiae are first discussed, focusing on the mechanism of glucose repression. Next, the function of the regulatory protein Mig1 in the signalling cascade of glucose repression is explained. The impact of Mig1-mediated glucose repression on metabolic functions is then discussed. It will be made clear that glucose repression is not confined to the above-mentioned example of mixed sugar metabolism. The last part of the review summarizes the effects glucose repression has on single metabolic functions. These components are then linked to a holistic view with the aim of understanding the effects of Mig1 on overall metabolism. Against this background possible physiological impacts of deletion/disruption of the MIG1 gene are discussed.

\section{Glucose control in S. cerevisiae}

The transcription of a number of genes is repressed when $S$. cerevisiae is cultivated on rapidly fermentable sugars, i.e. glucose, fructose and mannose; the transcription of genes essential for the catabolism of slowly fermentable sugars is repressed, as well as gluconeogenic and mitochondrial functions (Gancedo, 1992; Ronne 1995). The Crabtree effect, i.e. ethanol formation in the presence of oxygen in strains of Saccharomyces and related genera, can partially be explained by the lack of sufficient capacity for respiration resulting in overflow of pyruvate into ethanol fermentation reactions and partially by repression of mitochondrial function (de Deken, 1966; Fiechter et al., 1981; Käppeli, 1986). Since glucose is the most repressing sugar, the term 'glucose repression' is often employed. In some publications, glucose repression is used in terms of control of gene expression. In this review glucose repression is defined as transcriptional glucose repression, which together with mRNA degradation rate and translational efficiency controls gene expression. Besides the regulation of gene expression, glucose control includes two further regulatory mechanisms, namely accelerated protein degradation (carbon catabolite inactivation) and inhibition of the target enzyme (Fig. 1).

The concentration of a specific mRNA species in a cell is positively correlated with transcription efficiency and negatively with mRNA degradation. An increase in mRNA degradation in the presence of glucose, i.e. shorter half-lives of distinct mRNA populations, as a post-transcriptional mechanism has been reported (Federoff et al., 1983; Lombardo et al., 1992; Cereghino $\&$ Scheffler, 1996). The mechanism and control of

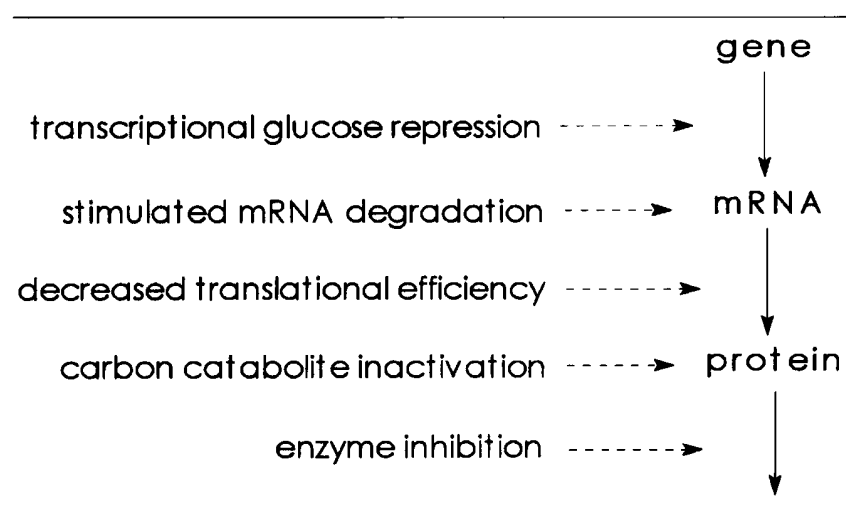

Fig. 1. Negative glucose control mechanisms. 
mRNA turnover, however, has not been given as much attention as glucose repression, but has been reviewed recently (Caponigro \& Parker, 1996).

Analogously to mRNA concentration, the concentration of a specific protein depends on translation efficiency and protein degradation. Knowledge about the impact of glucose on the translation rate in S. cerevisiae strains is limited (Parets Soler et al., 1987; Gallie, 1996), but translational efficiency and mRNA turnover seem to be intimately linked (Caponigro \& Parker, 1996). More attention has been paid to the post-translational modification of proteins triggered by glucose, generally referred to as carbon catabolite inactivation (Holzer, 1976). Carbon catabolite inactivation affects enzymes of peripheral functions, for example maltose permease and galactose permease (Görts, 1969; DeJuan \& Lagunas, 1986), as well as enzymes of central functions such as the gluconeogenic enzymes fructose-1,6-bisphosphatase and phosphoenolpyruvate carboxykinase (Holzer, 1976). Vacuolar and proteasomal proteolysis have recently been identified as possible mechanisms of degradation, the former particularly for carrier proteins (Schork et al., 1994; Riballo et al., 1995; Horak \& Wolf, 1997). Finally, glucose can inhibit the activities of various enzymes that are specifically related to sugars, as shown for enzymes that hydrolyse maltose and melibiose (Lazo et al., 1978; Siro \& Lövgren, 1978). Maltase has been reported to have a $K_{\mathrm{m}}$ value of $25 \mathrm{mM}$ for maltose, but it is competitively inhibited by glucose, for which it exhibits a low $K_{\mathbf{i}}$ value of about $1 \mathrm{mM}$ (Siro \& Lövgren, 1978). The existence of various glucose control mechanisms makes it clear that glucose repression is only one of the mechanisms within the framework of glucose control. This is important to keep in mind when results from genetically engineered strains are to be interpreted.

\section{The cascade of glucose repression and the role of MIG1}

The two best investigated glucose signalling pathways are the Ras-adenylate cyclase pathway and the main glucose repression pathway. The former has been reviewed by Thevelein (1994), the latter additionally by Entian \& Barnett (1992), Gancedo (1992), Trumbly (1992), Ronne (1995), and Entian \& Schüller (1997). The Ras-adenylate cyclase pathway is operative in glucosederepressed cells and acts transiently after glucose has been added. Sugar phosphorylation by any hexokinase (Hxk1, Hxk2, Glk1) leads to an accumulation of cAMP via the Ras-cAMP pathway, inducing a massive increase of cAMP-dependent protein kinase, which modifies a number of proteins post-translationally.

The main glucose repression pathway has the long-term function of keeping the cells repressed. It also includes the sensing of glucose, followed by a signal transfer and finally the physical binding of a repressor (downstream effector) to the promoter of the repressed gene. The key elements are the sensoring hexokinase PII ( $\mathrm{Hxk} 2)$, the serine/threonine protein kinase Snf1 and the DNAbinding repressor Mig1. Knowledge about this repres-

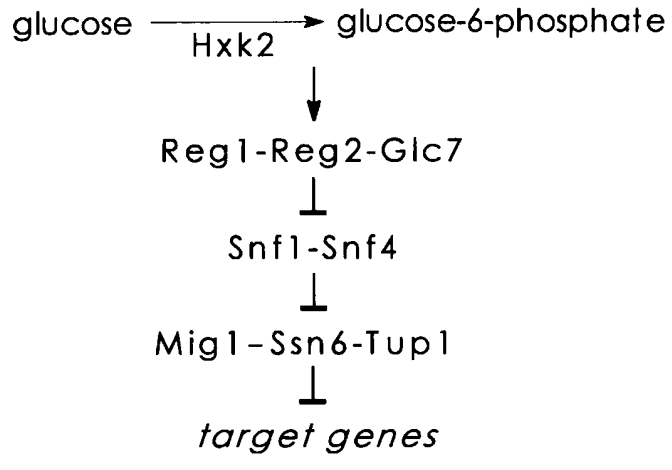

Fig. 2. Key elements involved in the main glucose repression pathway.

sion cascade stems from genetic research, where derepression and repression mutants helped to identify the genes involved. Kinases seem to play a crucial role in this cascade, such as hexokinase PII (encoded by $H X K 2$, which is identical to HEX1), which phosphorylates rapidly fermentable sugars and exhibits protein kinase activity, and a protein kinase that acts further downstream (encoded by SNF1, which is identical to CAT1), as illustrated in Fig. 2. Snf1 together with Snf4 (Cat3), is part of a protein kinase complex. It is activated by phosphorylation under derepressing conditions, and inactivated by dephosphorylation under repressing conditions (Jiang \& Carlson, 1996; Wilson et al., 1996). The phosphorylation correlates with a high AMP: ATP ratio, indicating the role of adenine nucleotides in glucose signalling (Wilson et al., 1996; Hardie \& Carling, 1997). The gene function of GLC7, as well as those of REG1 (HEX2) and REG2 are known for their antagonism to Snf1; they code for the protein phosphatase 1 complex and are therefore assumed to dephosphorylate Snf1 (Neigeborn, 1987; Tu \& Carlson, 1995; Frederick \& Tatchell, 1996; Jiang \& Carlson, 1996). Moreover, Reg1 has been reported to be involved in the signal transfer for stimulated mRNA degradation (Cereghino \& Scheffler, 1996). The precise interrelation of elements in the upper part of the signalling cascade is less well understood and will not be discussed further.

In 1990 Nehlin \& Ronne cloned the MIG1 gene (multicopy inhibitor of $\underline{G} A L$ gene expression). It is identical to SSN1 (Vallier \& Carlson, 1994) and to CAT4 (Schüller \& Entian, 1991). Its gene product is a $\mathrm{C}_{2} \mathrm{H}_{2}$ zinc finger protein, which resembles the mammalian Egr and Wilms' tumour proteins, the CreA repressor in Aspergillus nidulans and the Mig1 repressor in Kluyveromyces lactis (Nehlin \& Ronne, 1990; Dowzer \& Kelly, 1991; Cassart et al., 1995). The MIG1 promoter has been reported to be auto-regulated (Lundin et al., 1994). Transcriptional repression is effected by a protein complex consisting of Ssn6, Tup1 and Mig1. Whilst Ssn6 and Tup1 confer the actual repression, the DNA-binding Mig1 directs them to the respective promoters (Keleher et al., 1992; Treitel \& Carlson, 1995) (Fig. 2). Mig1 is increasingly phosphory- 
Table 1. Impact of the MIG1 gene product on the expression of other genes

\begin{tabular}{|c|c|c|c|c|c|c|c|}
\hline \multirow{2}{*}{$\begin{array}{l}\text { Part of } \\
\text { metabolism } \\
\text { affected }\end{array}$} & \multirow{2}{*}{$\begin{array}{c}\text { Gene } \\
\text { name(s) }\end{array}$} & \multirow{2}{*}{$\begin{array}{l}\text { Function of } \\
\text { gene product }\end{array}$} & \multirow[t]{2}{*}{ EC no. } & \multirow{2}{*}{$\begin{array}{l}\text { (Putative) } \\
\text { Mgl-binding } \\
\text { site }\end{array}$} & \multicolumn{2}{|c|}{ Physiological effect after MIG1: } & \multirow[t]{2}{*}{ Reference(s) } \\
\hline & & & & & Disruption & Overexpression & \\
\hline \multirow[t]{14}{*}{ Peripheral } & FPS1 & $\begin{array}{l}\text { Osmosensitive glycerol } \\
\text { uptake/efflux facilitator }\end{array}$ & & Yes & Yes & NT & $\begin{array}{l}\text { Lundin et al. (1994); Luyten et al. (1995); } \\
\text { Klein et al. (1996) }\end{array}$ \\
\hline & GAL1 & Galactokinase & 2.7 .1 .6 & Yes & Yes & Yes & $\begin{array}{l}\text { Nehlin \& Ronne (1990); Nehlin et al. } \\
\text { (1991); Lundin et al. (1994) }\end{array}$ \\
\hline & GAL3 & Inducer function protein & & Yes & NT & NT & Lundin et al. (1994) \\
\hline & GAL4 & Transcriptional activator & & Yes & Yes & Yes & $\begin{array}{l}\text { Nehlin \& Ronne (1990); Nehlin et al. } \\
\text { (1991); Lundin et al. (1994) }\end{array}$ \\
\hline & $\begin{array}{l}\text { GALS } \\
(P G M 2)\end{array}$ & Phosphoglucomutase 2 & 5.4 .2 .2 & Yes & NT & NT & Fu et al. (1995) \\
\hline & GLK1 & Glucokinase 1 & 2.7 .1 .2 & Yes & $\mathrm{NT}$ & NT & Sierkstra et al. (1992); de Winde et al.(1996) \\
\hline & $H X K 1$ & Hexokinase 1 & 2.7 .1 .1 & Yes & NT & NT & Sierkstra et al. (1992) \\
\hline & $\begin{array}{l}H X T 2,3 \\
H X T 4 \\
(L G T 1)\end{array}$ & $\begin{array}{l}\text { Hexose transporter } \\
\text { glucose sensor }\end{array}$ & & Yes & Yes & NT & $\begin{array}{l}\text { Özcan \& Johnston (1995); Reifenberger et } \\
\text { al. (1995); Özcan \& Johnston (1996); } \\
\text { Walsh et al. (1996) }\end{array}$ \\
\hline & $S N F 3$ & Glucose sensor, hexose transporter & & & Yes & NT & $\begin{array}{l}\text { Wendell \& Bisson (1994); Özcan \& } \\
\text { Johnston (1995); Reifeberger et al. (1995); } \\
\text { Walsh et al. (1996) }\end{array}$ \\
\hline & $M A L R$ & Regulatory protein & & Yes & Yes & Yes & Lundin et al. (1994); Hu et al. (1995) \\
\hline & MALS & Maltase & 3.2 .1 .20 & Yes & Yes & Yes & Lundin et al. (1994); Hu et al. (1995) \\
\hline & MALT & Maltose transporter & & Yes & Yes & Yes & Lundin et al. (1994); Hu et al. (1995) \\
\hline & MEL1 & Melibiase & 3.2 .1 .22 & Yes & NT & NT & Lundin et al. (1994) \\
\hline & sUC2 & Invertase & 3.2 .1 .26 & Yes & Yes & Yes & $\begin{array}{l}\text { Nehlin \& Ronne (1990); Lundin et al. } \\
\text { (1994) }\end{array}$ \\
\hline \multirow[t]{13}{*}{ Central } & CAT8 & $\begin{array}{l}\text { Regulatory protein Cat8p, } \\
\text { derepressor of FBP1, PCK1, ICL1 } \\
\text { and } A C S 1\end{array}$ & & Yes & Yes & NT & $\begin{array}{l}\text { Hedges et al. (1995); Kratzer \& Schüller } \\
\text { (1997) }\end{array}$ \\
\hline & COXSB & Cytochrome-c oxidase subunit $\mathrm{Vb}$ & 1.9 .3 .1 & Yes & NT & NT & $\begin{array}{l}\text { Hodge et al. (1990); de Winde \& Grivell } \\
\text { (1993) }\end{array}$ \\
\hline & CYT1 & Cytochrome $c_{1}$ & & Yes & NT & NT & $\begin{array}{l}\text { Oechsner } \text { et al. (1992); de Winde \& Grivell } \\
\text { (1993) }\end{array}$ \\
\hline & $F B P 1$ & Fructose-1,6-bisphosphatase & 3.1 .3 .11 & Yes & No & No & $\begin{array}{l}\text { Mercado et al. (1991); Mercado \& } \\
\text { Gancedo (1992); Lundin et al. (1994) }\end{array}$ \\
\hline & $\begin{array}{l}\text { GGS1 } \\
\text { (BYP1-3, } \\
\text { CIF1, } \\
\text { FDP1, } \\
\text { TPS1, } \\
\text { TSS1) }\end{array}$ & $\begin{array}{l}\text { Subunit of trehalose-6-phosphate } \\
\text { synthase, regulator of carbon } \\
\text { catabolite inactivation, controller of } \\
\text { glucose flux into glycolysis }\end{array}$ & 2.4.1.15 & Yes & NT & NT & $\begin{array}{l}\text { Bell et al. (1992); Gonzílez et al. (1992); } \\
\text { Hohmann et al. (1992); Lundin et al. } \\
\text { (1994) }\end{array}$ \\
\hline & HAP4 & $\begin{array}{l}\text { Activation factor for transcription of } \\
\text { genes involved in the oxidative } \\
\text { phosphorylation, tricarboxylic acid } \\
\text { cycle and gluconeogenesis }\end{array}$ & & Yes & No & NT & $\begin{array}{l}\text { Forsburg \& Guarente (1989); Gancedo } \\
\text { (1992); de Winde \& Grivell (1993); } \\
\text { Lundin et al. (1994); Rosenkrantz et al. } \\
\text { (1994); Schlaepfer et al. (1994); Crawford } \\
\text { et al. (1995) }\end{array}$ \\
\hline & ICL1 & Isocitrate lyase & 4.1.3.1 & Yes & No & NT & Schöler \& Schüller (1993) \\
\hline & MIG1 & Repressor protein & & Yes & NT & NT & Lundin et al. (1994) \\
\hline & MLS1 & Malate synthase & 4.1.3.2 & Yes & NT & NT & Schöler \& Schüller (1993) \\
\hline & NTH1 & Neutral trehalase & 3.2 .1 .28 & Yes & NT & NT & Kopp et al. (1993) \\
\hline & PCK1 & Phosphoenolpyruvate carboxykinase & 4.1.1.49 & Yes & No & No & Mercardo \& Gancedo (1992) \\
\hline & PDC1 & Pyruvate decarboxylase (isoenzyme 1) & 4.1.1.1 & Yes & NT & NT & Lundin et al. (1994) \\
\hline & QCR8,9 & $\begin{array}{l}\text { Ubiquinol-cytochrome- } c \\
\text { oxidoreductase subunits VIII and IX }\end{array}$ & 1.10 .2 .2 & Yes & NT & NT & $\begin{array}{l}\text { Maarse } \text { et al. (1988); de Winde \& Grivell } \\
\text { (1993) }\end{array}$ \\
\hline
\end{tabular}

NT, Not tested.

lated with decreasing glucose availability, possibly by Snf1 protein kinase, thus standing under negative control of Snf1 (Treitel \& Carlson, 1995; DeVit \& Johnston, 1996). The putative phosphorylation site as well as the effector domain of Mig1 were identified with the help of deletion mapping (Östling et al., 1996). Apart from Mig1-redundant repressors, other probable DNAbinding proteins that guide Ssn6-Tup1 to different promoters are Rox1, $\alpha 2-\mathrm{Mcm} 1$, a1- $\alpha 2$ and Rgt1 for hypoxic, MATa-specific, haploid-specific and glucoseinduced genes, respectively (Keleher et al., 1992; Deckert et al., 1995; Özcan et al., 1996).

There are generally three strategies that help to reveal Mig1-mediated repression: the first is a search for putative Mig1-binding sites on the promoters of glucoserepressible genes, and the consensus motif has been suggested to be $(\mathrm{G} / \mathrm{C})(\mathrm{C} / \mathrm{T}) \mathrm{GG}(\mathrm{G} / \mathrm{A}) \mathrm{G}$ (Nehlin \& Ronne, 1990). The existence of such a consensus sequence on a gene promoter is, however, no more than an indication that Mig1 might actually bind.

A second and qualitatively better strategy is provided by assays that prove Mig1 binding to the alleged promoter sequence in vitro (Nehlin \& Ronne, 1990). In a footprint assay, the endonuclease DNase I hydrolyses DNA that is not covered by bound Mig1, the undigested sequence representing the putative binding sequence. In an oligonucleotide gel shift experiment, Mig1 is incubated with a DNA fragment that contains a putative Mig1- 
binding site and that can be generated by saturation mutagenesis. If the mobility of the DNA fragment in an electrophoresis gel is decreased, Mig1 must have bound to it. The agarose gel shift assay is based on the observation that protein (Mig1)-binding to DNA causes a bend in the DNA and that the relative electrophoretic mobility of the protein-DNA complex is dependent on the protein-binding site on the respective DNA strand. By examining the mobility of various protein-DNA complexes obtained by cleaving DNA with different restriction enzymes the localization of the specific binding site can therefore be identified. These assays are performed in vitro, and therefore do not necessarily reflect in vivo affinities. In the context of Mig1 binding to, and affinity for, a particular DNA sequence, it must be stressed that the degree of repression is dependent on this DNA sequence, implying that glucose repression is not a pure on/off mechanism (Lundin et al., 1994).

The third strategy is to investigate the physiological consequences of MIG1 deletion/disruption and/or MIG1 overexpression. Again, no absolute evidence can be provided; an example is the unchanged physiology of a $\Delta$ mig1 mutant, which could well be explained by a Mig1-redundant protein, i.e. a protein that is similar to Mig1 and that can partly substitute for it. Recently, a second repressor, Mig2, 71\% identical to Mig1, as well as a related protein with unknown function, Yer028, have been identified (Lutfiyya \& Johnston, 1996). Mig2 has been shown to bind to some of the Mig1-binding sites. A double deletion mutant $\Delta$ mig1 $\Delta$ mig 2 yielded a considerably higher derepression than the single $\Delta m i g 1$ mutant for SUC2 expression, but not for PCK1, FBP1, HXT2 and GAL1 (Lutfiyya \& Johnston, 1996). In view of the lack of knowledge about these redundant functions, the focus of this review will be kept on the function of MIG1. The eventuality of Mig1-related activation of transcription as well as a binding of activators on to the Mig1 consensus sequence will be discussed below.

\section{Mig1-controlled metabolic functions}

Since MIG1 plays a pivotal role in glucose repression for many metabolic functions, they will be discussed one at a time. Metabolic functions can be grouped into central metabolism, which comprises glycolysis, the tricarboxylic acid cycle, fermentative and respirative functions, the glyoxylate shunt and gluconeogenesis, and the peripheral functions, such as the catabolism of sugars to the level of glucose-6-phosphate. Table 1 gives a survey of genes that are proposed to be under Mig1-mediated glucose repression.

\section{Metabolism of disaccharides and trisaccharides}

The disaccharides sucrose and melibiose and the trisaccharide raffinose are hydrolysed outside the cell membrane into monosaccharides, which are then taken up by the cell. Secretion of hydrolytic enzymes is essential because there are no major transport systems for melibiose and raffinose. Since beet molasses contains $40-50 \%$ sucrose and up to $2 \%$ raffinose, extracellular sugar hydrolysis is important in industrial baker's yeast production, where beet molasses often is utilized as the main carbon source.

Invertase (EC 3.2.1.26) hydrolyses sucrose into glucose and fructose (Fig. 3). SUC2 is the most commonly found structural gene in laboratory strains. SUC2 transcription is repressed both by the complete absence of glucose and by high glucose concentrations, but requires low levels of glucose for maximal transcription (Özcan et al., 1997). A MIG1 deletion in a haploid strain resulted in a ninefold increase of SUC2 mRNA levels when glucose was used as carbon source (Nehlin \& Ronne, 1990). A MIG1 disruption in an industrial baker's yeast strain as well as in another laboratory strain also led to a significant glucose derepression (Klein et al., 1996; Olsson et al., 1997). Nehlin \& Ronne (1990) reported that MIG1 overexpression results in an aggravated repression of SUC2 expression and proved by DNase I footprinting that Mig1 binds to the SUC2 upstream region, identifying possible recognition sequences. A second significant contribution to repression mediation is given by Mig2, as shown in single and double deletion mutants (Lutfiyya \& Johnston, 1996). Thirdly, SUC2 mRNA stability is decreased in the presence of glucose (Cereghino \& Scheffler, 1995). Besides extracellular sucrose hydrolysis, direct sucrose uptake has been reported, playing an important role under repressing conditions (Santos et al., 1982; Mwesigye \& Barford, 1996).

Melibiase (EC 3.2.1.22) hydrolyses melibiose into glucose and galactose (Fig. 3). It is encoded by the MEL genes, of which MEL1 is the most thoroughly investigated (Sumner-Smith et al., 1985; Naumov et al., 1996). MEL1 is normally present in Saccharomyces carlsbergensis, but not in $S$. cerevisiae and belongs to the coordinately galactose-inducible and glucose-repressible $G A L / M E L$ gene family (see also following section). There is evidence that MEL1 expression is under Gal4 control (Post-Beittenmiller et al., 1984; Johnston, 1987), whose expression is under Mig1 control (Nehlin et al., 1991). Moreover, there are good indications that Mig1 directly binds to the MEL1 upstream sequence, as verified for example by DNase I footprinting (Lundin $e t$ al., 1994).

Maltose metabolism is important for brewing and bread-making. Malt brewer's wort contains $50-60 \%$ maltose, while plain dough mainly is composed of starch, which is made available to the yeast in the form of maltose, after hydrolysis by amylases. In contrast to the above-mentioned extracellular sugar hydrolysis, maltose is first taken up via maltose permease and then hydrolysed intracellularly by maltase (EC 3.2.1.20) into two units of glucose (Fig. 3). Maltose permease is encoded by $M A L T$. It plays a crucial role for maltose metabolism, being essential not only for maltose uptake, but also indirectly for maltose induction of the $M A L$ genes: $M A L$ genes cannot be induced if maltose cannot 


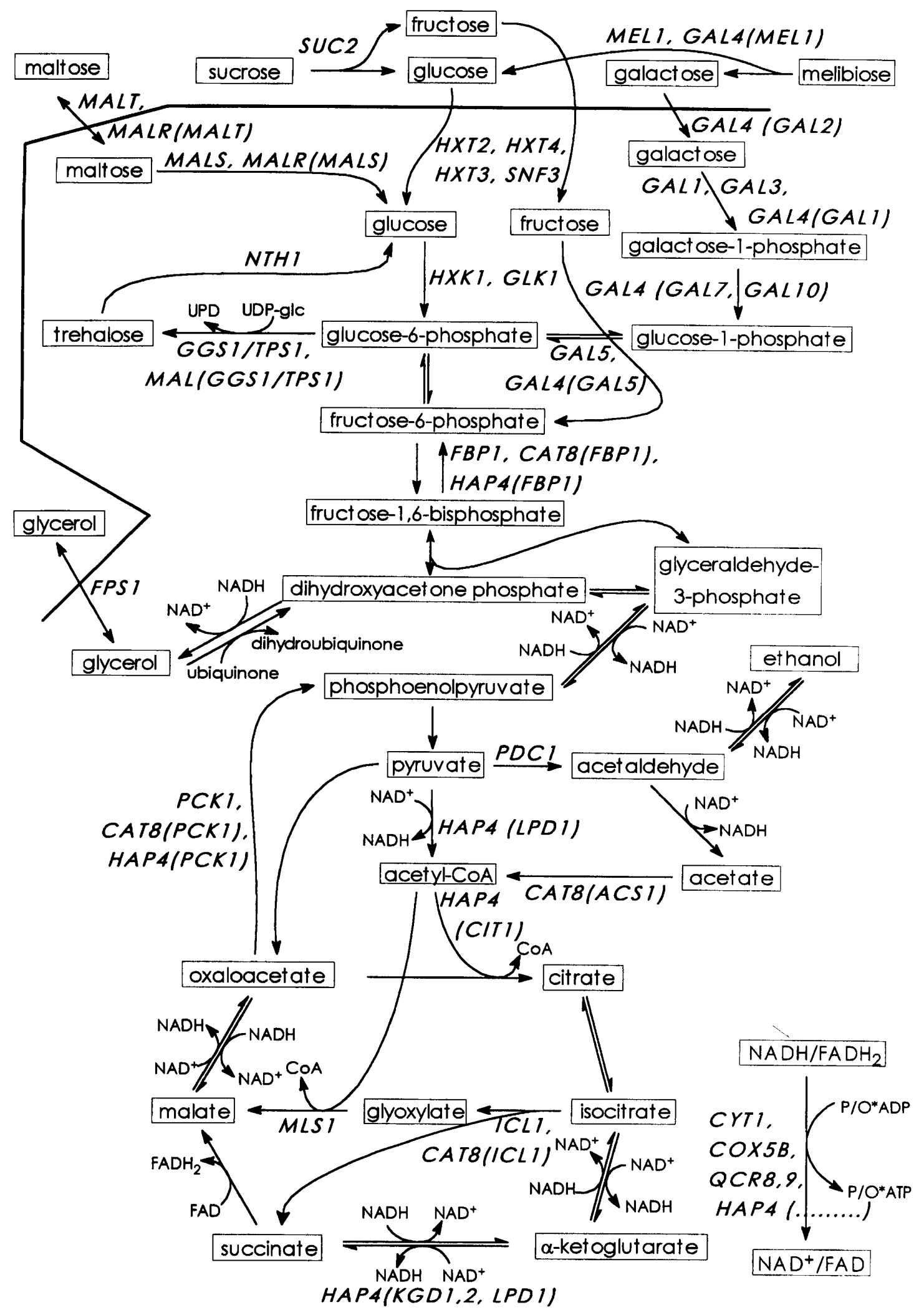

Fig. 3. Synopsis of (putative) Mig1-repressed genes and the metabolic role of their expression products; genes are given in brackets when they are under control of a Mig1-repressed regulator such as MalR, Gal4, Cat8 or Hap4. 
be transported into the cell. Maltase is encoded by MALS. The third gene involved is MALR, which encodes a regulatory zinc finger protein essential for maltose induction and glucose repression of MALT and MALS expression.

$\mathrm{Hu}$ et al. (1995) identified Mig1-binding sites on promoters of MAL genes and quantified the glucose derepression caused by MIG1 deletion as well as the increase in repression that is caused by MIG1 overexpression. Glucose control was shown to be partly mediated by, and partly independent of, Mig1. The latter contribution could be due to other repressors (glucose repression), but is certainly due to other glucose control mechanisms, for example catabolite inactivation of maltose permease and the stimulated degradation of MALS transcripts (Görts, 1969; Federoff et al., 1983). The Ras-cAMP pathway has been shown to be involved in the stimulated degradation of MALT mRNA and maltose permease inactivation (Wanke et al., 1997). Since Mig1 regulates the transcription of the structural genes both directly, and indirectly via MalR, MAL gene control can be referred to as dual-level control.

\section{Galactose metabolism}

Galactose utilization and GAL gene regulation have been excellently reviewed by Johnston \& Carlson (1992) and also by Lohr et al. (1995). Galactose is taken up by galactose permease (encoded by GAL2), phosphorylated by galactokinase (EC 2.7.1.6, encoded by GAL1), and further converted to glucose-6-phosphate by enzymes of the Leloir pathway, which are encoded by GAL7, GAL10 (Fig. 3) and GAL5 (PGM2) (encoding the major isozyme of phosphoglucomutase, EC 5.4.2.2, which, in the reverse direction, is pivotal for glycogen and trehalose anabolism). The transcription of GAL2, GAL1, GAL7, GAL10 and GAL5 is activated by the binding of the zinc finger transcription activator Gal4 on to their upstream sequences. Concomitant binding of Gal80 to the activation region prevents the transcriptional activation and is neutralized by the galactose-dependent binding of the regulatory protein $\mathrm{Gal} 3$, or, less efficiently, by that of the related Gal1 protein, to Gal80 (Johnston, 1987; Oh \& Hopper, 1990; Zenke et al., 1996; Yano \& Fukasawa, 1997). Phosphorylation of Gal4 seems to be necessary for its competency to activate $G A L$ transcription (Mylin et al., 1990; Sadowski et al., 1996).

Both GAL4 and GAL1 are repressed by Mig1, as proven biochemically by DNase I footprinting, and physiologically by MIG1 deletion and MIG1 overexpression (Nehlin \& Ronne, 1990; Nehlin et al., 1991). Thus, GAL1 is under dual-level control (Mig1 and Gal4), whereas GAL2, GAL7 and GAL10 are at least under indirect MIG1 control. Moreover, Mig1 has been shown to bind to the GAL3 promoter and to have a consensus sequence on the GAL5 promoter (Lundin et al., 1994; Fu et al., 1995). Interestingly, Gal5 has been reported to be post-translationally modified in response to glucose and galactose, however without apparent changes in enzymic activity (Fu et al., 1995). Thus, the physiological significance of this observation remains unclear. As concerns the overall glucose control, analogously to maltose permease, galactose permease is subject to catabolite inactivation (DeJuan \& Lagunas, 1986; Horak \& Wolf, 1997).

\section{Metabolism of glucose, fructose and mannose}

The sugars glucose, fructose and mannose are often referred to as rapidly fermentable sugars, with fructose and mannose being able to exert 'glucose repression' in many cases, but to a lesser extent than glucose (Gancedo, 1992; Thevelein, 1994). As to the uptake system for these sugars, the gene products of HXT1-17 and SNF3 are possible putative transporters for their facilitated diffusion (Celenza et al., 1988; Reifenberger et al., 1995; Kruckeberg, 1996; Fig. 3). Hxt1 through Hxt4, Hxt6 and $\mathrm{Hxt} 7$ are strongly suggested to mediate hexose uptake (Reifenberger et al., 1995). Amongst the abovementioned putative transporters, Snf3 and $\mathrm{Hxt} 2$ have so far been shown to be involved in regulation of glucose transport and in glucose sensing (Ko et al., 1993; Wendell \& Bisson, 1994; Liang \& Gaber, 1996; Walsh et al., 1996). MIG1 deletion mutants have shown that HXT2, HXT4 (=LGT1) and SNF3 are subject to strong Mig1-mediated glucose repression, whereas Mig1 has a lower repressive impact on HXT3 expression (Ozcan \& Johnston, 1995). The weak glucose repression of $H X T 3$ stands in contrast to a general induction of HXT3 by glucose. It could be explained by a fine-tuned Mig1mediated repression, i.e. a balance between glucose induction and repression gives the appropriate gene expression. As concerns HXT2 and HXT4 transcription, maximum transcription occurs at low glucose concentrations, since Rgt1-mediated repression is operative under complete absence of glucose and Mig1 mediates repression at high glucose concentrations (Özcan \& Johnston, 1996; Özcan et al., 1996). Full derepression of HXT2 in the presence of glucose has been reported for a $\Delta m i g 1 \Delta$ mig2 $\Delta y e r 028$ triple mutant (Lutfiyya \& Johnston, 1996). In conclusion, glucose repression is mediated by Mig1 (Mig2, Yer028) to SNF3, HXT2 and HXT4, whose gene products in turn may act as glucose sensors and be involved in the regulation of glucose transport. The glucose transport system has been shown to be subject to catabolite inactivation (Busturia \& Lagunas, 1986).

Uptake of rapidly fermentable sugars is followed by phosphorylation by hexokinase PI or hexokinase PII (EC 2.7.1.1) or glucokinase (specific for glucose and mannose, EC 2.7.1.2), encoded by $H X K 1, H X K 2$, and $G L K 1$, respectively. The $H X K 2$ gene plays a major role in the signalling cascade of the main glucose repression pathway (Fig. 2); the steady state level of $H X K 2$ mRNA is high in the presence of glucose and drastically reduced in the presence of ethanol, glycerol or galactose (Herrero et al., 1995). The opposite is the case for HXK1 and GLK1 mRNAs, raising the question as to the physiological task of Hxk1 and Glk1, especially under repressing conditions (Herrero et al., 1995). The implication is likely to be a rapid initial response of glucose 
control for example via the Ras-adenylate cyclase pathway (transcriptional repression, mRNA degradation, catabolite inactivation), preceding a sustained long-term response in the form of glucose repression, where Hxk2 is involved (de Winde et al., 1996; Sanz et al., 1996). There is evidence that Mig1 is involved in glucose repression of $H X K 1$ and GLK1 (Sierkstra et al., 1992; de Winde et al., 1996).

The function of the GGS1/TPS1 gene is essential for growth on glucose since it directly or indirectly affects the influx of glucose into the glycolytic pathway, for which Thevelein \& Hohmann (1995) have proposed three models. Ggs1/Tps1 has been shown to be a positive regulator of fructose-1,6-bisphosphatase and maltose permease inactivation and of the stimulated mRNA degradation of FBP1, PCK1 and MALT transcripts (Bell et al., 1992; Wanke et al., 1997; Dr Zhikang Yin, personal communication). There is a putative Mig1-binding sequence on the GGS1/TPS1 promoter (González et al., 1992), but in vitro binding with Mig1 could not be confirmed in oligonucleotide gel shift experiments (Lundin et al., 1994).

\section{Trehalose metabolism and glycerol influx/efflux}

Glycogen and trehalose are the main storage carbohydrates in yeast. While glycogen is suggested to function as a main energy source, trehalose is recognized as a stress protectant that is essential for preservation and survival (Panek, 1991). The two key reactions in trehalose anabolism are catalysed by the trehalose-6phosphate synthase/phosphatase complex, whose components have been reported to be subject to glucose repression and catabolite inactivation (François et al., 1991; Thevelein \& Hohmann, 1995). Mig1 is hypothesized to bind to the promoter of one encoding gene, GGS1/TPS1 (González et al., 1992) (Fig. 3). Moreover, there is evidence that the constitutive expression of $M A L$ genes accelerates trehalose synthesis during growth on glucose (Petit \& François, 1994). Therefore, a dual-level control of GGS1/TPS1, both directly by Mig1 and indirectly by gene products of MAL genes, can be assumed.

Trehalose is hydrolysed to glucose by neutral trehalase (EC 3.2.1.28), encoded by NTH1 (Nwaka et al., 1995), on whose promoter a possible Mig1-binding site has been found (Kopp et al., 1993). A similar putative function of Mig1 on genes for two antagonizing reaction steps (GGS1/TPS1 and NTH1) might implicate futile cycling in the absense of glucose and/or in $\Delta$ mig1 mutants if there were not any further glucose control mechanism. Trehalose-6-phosphate synthase and neutral trehalase, however, have been shown to be, respectively, down- and up-regulated by post-translational modification in response to glucose (François et al., 1991; Panek, 1991).

FPS1 encodes a channel protein that facilitates glycerol uptake and efflux (Luyten et al., 1995) (Fig. 3). An oligonucleotide gel shift experiment proved Mig1 binding to a consensus sequence on the FPS1 promoter
(Lundin et al., 1994). This finding bears relevance for the anaerobic physiology of $S$. cerevisiae where glycerol secretion is necessary for the oxidation of excessive NADH. A deletion of MIG1 would allow more glycerol to be secreted if secretion via Fps1 were the ratecontrolling step. Two $\Delta m i g 1$ strains were shown to secrete significantly higher amounts of glycerol compared to their parental strains (Klein et al., 1996). This finding, however, does not exclude the possible influence of Mig1 on the other genes in the glycerol production pathway, such as GPD1.

\section{Gluconeogenesis and glyoxylate shunt}

Due to the unidirectional glycolytic reactions of phosphofructokinase and pyruvate kinase, the functions of FBP1, encoding fructose-1,6-bisphosphatase (EC 3.1.3.11), and PCK1, encoding phosphoenolpyruvate carboxykinase (EC 4.1.1.49), are essential for gluconeogenesis (Fig. 3). Both enzymes are subject to catabolite inactivation (Holzer, 1976). Both FBP1 and PCK1 have three consensus sequences on their promoters: for Mig1, for the activating Hap2/Hap3/Hap4/Hap5 complex (see below), and for the derepressing zinc finger Cat8 protein. Cat8 is related to Gal4, requires phosphorylation for activation (hypothetically by Snf1) and its expression is under the control of Mig1 (itself controlled via phosphorylation by Snf1) (Mercado et al., 1991; Mercado \& Gancedo, 1992; Hedges et al., 1995; Randez-Gil et al., 1997). Neither MIG1 overexpression nor MIG1 deletion had a significant effect on FBP1 and PCK1 expression (Mercado et al., 1991; Mercado \& Gancedo, 1992). The exceptionally high sensitivity of the mRNAs of these genes towards glucose can at least be partly explained by stimulated mRNA degradation, and has been shown to be independent of Mig1 (Mercado et al., 1994; Yin et al., 1996).

In the glyoxylate shunt, isocitrate and acetyl-CoA are converted to succinate and malate, without losing $\mathrm{CO}_{2}$, in contrast to the tricarboxylic acid cycle. Preceding gluconeogenesis, this reaction sequence is the essential link between acetyl-CoA and oxaloacetate when yeast is growing on non-fermentable substrates, such as ethanol or acetate, and drastically repressed in the presence of glucose (Gancedo \& Serrano, 1989). The glyoxylate shunt is catalysed by two enzymes: isocitrate lyase (EC 4.1.3.1, encoded by $I C L 1$ ) and malate synthase (EC 4.1.3.2, encoded by $M L S 1$ ) (Fig. 3). Both genes contain putative Mig1-binding sites in their promoter regions (Schöler \& Schüller, 1993). Moreover, the expression of ICL1 and of ACS1 depends on the derepressing CAT8 gene function (Hedges et al., 1995; Kratzer \& Schüller, 1997). ACS1 encodes the glucose-repressible acetyl-CoA synthetase (EC 6.2.1.1), which is essential for the entry of ethanol/acetate into the tricarboxylic acid cycle.

\section{Fermentative functions, tricarboxylic acid cycle and respirative functions}

The main carbon flux splits at the level of pyruvate into the tricarboxylic acid cycle and alcoholic fermentation 
(Fig. 3). Activities of the enzymes in each of the two branches can be assumed metabolically to control the ratio of the bifurcating fluxes. Pyruvate decarboxylase (EC 4.1.1.1) converts pyruvate to acetaldehyde, the first step in ethanol formation. The most important gene relative to growth on glucose is PDC1 (Hohmann, 1991, 1993). DNase I footprinting revealed that Mig1 binds on to the promoter of PDC1 (Lundin et al., 1994), which seemingly stands in contradiction to the finding that PDC1 expression is increased in the presence of glucose (Schmitt et al., 1983). This issue will be further discussed below.

The first step of the tricarboxylic acid cycle is catalysed by mitochondrial citrate synthase (EC 4.1.3.7), encoded by CIT1 and CIT3 (Fig. 3). The expression of the CIT1 gene requires an activation complex that contains Hap4, which is under MIG1 control (Rosenkrantz et al., 1994). The conversion from $\alpha$-ketoglutarate to succinate is catalysed by the $\alpha$-ketoglutarate dehydrogenase complex, whose components are encoded by $K G D 1, K G D 2$ and LPD1. All three genes have been shown to be activated by Hap4 (de Winde \& Grivell, 1993). The dihydrolipoyl dehydrogenase (encoded by LPD1) is also a component of the pyruvate dehydrogenase complex; thus the repression of one gene affects two enzyme complexes (Fig. 3 ).

Oxidative phosphorylation takes place in the mitochondria. The transcription of a number of genes that encode components of the respiratory chain and of the mitochondrial gene expression machinery is induced by oxygen and repressed by fermentable carbon sources (de Winde \& Grivell, 1993). The genes HAP2, HAP3, HAP4 and HAP5 code for proteins that form a promoterbinding, activating complex and that regulate different respiratory functions, Hap4 appearing to be limiting in this complex (Johnston \& Carlson, 1992). This complex activates transcription of a number of respiratory genes, such as CYC1, CYB2, CYT1, QCR2,7,8, COX4,5A, $5 B, 6, H E M 1$ and YHG. Furthermore, Hap4-binding sequences have been identified on the promoters of QCR1, RIP1, QCR6,9, COX6B and HEM2 (de Winde \& Grivell, 1993; Schlaepfer et al., 1994; Crawford et al., 1995). This enumeration of (putatively) controlled mitochondrial genes underlines the pivotal role the Hap2/Hap3/Hap4/Hap5 complex plays in the expression of these genes. HAP4 overexpression has been reported to result in a more oxidative metabolism with a higher specific growth rate and an increase in cell mass yield by $45 \%$ (Blom et al., 1997).

HAP4 has a Mig1-binding site on its promoter as verified by oligonucleotide gel shift experiments (Lundin et al., 1994); moreover HAP2 and HAP4 have been shown to be glucose-repressible (Pinkham \& Guarente, 1985; Forsburg \& Guarente, 1989). It has, however, been reported that a MIG1 deletion did not result in a derepression of $H A P 4$, suggesting a redundant repression mechanism (Lundin et al., 1994). Finally, Mig1binding sites (direct control) have been identified on the promoters of the genes CYT1, COX $5 B$ and QCR 8,9
(Maarse et al., 1988; Hodge et al., 1990; Oechsner et al., 1992; de Winde \& Grivell, 1993).

\section{Possible putative impacts of MIG1 deletion/disruption: a holistic view}

Potential candidates for Mig1-mediated glucose repression are those genes that bear the Mig1 consensus sequence on their promoters, that have promoters on to which Mig1 has been shown to bind in vitro, and/or that show a physiological effect in $\Delta$ mig1 or $M I G 1^{\mathrm{c}}$ mutants. These genes have been discussed previously and are summarized in Table 1.

A synopsis is given in Fig. 3 for the main carbon pathways in the cell and for genes that encode key enzymes or effectors and that stand under direct or indirect Mig1-mediated repression. An interesting feature of Mig1-mediated repression is dual-level control. Mig1 mediates repression by binding on to the promoter of both the functional gene and of the relative regulator gene, such as MALR, GAL4, CAT8 and HAP4, which respectively encode the regulatory protein for $M A L$ genes, the $G A L$-gene activator, a derepressor for gluconeogenic genes and a subunit of the transcriptional activator for mitochondrial genes (Nehlin et al., 1991; de Winde \& Grivell, 1993; Hedges et al., 1995; Hu et al., 1995). Such a dual-level control is a potential amplifier of glucose repression.

The controlled genes can be divided into peripheral functions, i.e. metabolism of saccharides to glucose-6phosphate as well as further influx/efflux functions, and central functions, such as gluconeogenesis, the glyoxylate shunt, fermentative functions, the tricarboxylic acid cycle and oxidative phosphorylation. As can be concluded from Table 1, MIG1 deletion has a greater impact on peripheral functions than on central metabolism. However, a deletion/disruption of MIG1 is not able to eliminate glucose repression entirely of galactose, maltose and sucrose metabolism, as substantial Mig1independent glucose control mechanisms do exist for the GAL, MAL and SUC systems (Nehlin \& Ronne, 1990; Nehlin et al., 1991; Hu et al., 1995). These results are relevant for industrial yeast processes because glucose, which is most commonly present in industrial carbon sources, delays the uptake of the sugars and unnecessarily prolongs the production process. An effective alleviation of glucose control would help to achieve a better process economy for the cultivation of baker's yeast, alcohol fermentation and bread-making.

The central functions putatively affected by Mig1 have not been investigated as thoroughly as the peripheral ones, but the data presented give a sound indication that glucose repression, which is well-known for gluconeogenesis, the glyoxylate shunt and respiration (Fiechter et al., 1981), is partly mediated by Mig1. The finding that CAT8 is derepressed in a $\triangle$ mig1 strain, whereas Cat8controlled FBP1, PCK1 and ICL1 are not, gives a clear hint of the existence of other repressors such as Mig2 or 
a post-translational modification of an effector such as the phosphorylation of the derepressor Cat8 (Hedges et al., 1995; Randez-Gil et al., 1997). Moreover, control mechanisms other than glucose repression, for example higher mRNA degradation, a decreased translational efficiency or carbon catabolite inactivation, are operative, as discussed above (Fig. 1).

The presence of a Mig1-binding site on the promoter of the PDC1 gene, which is known to be induced by glucose, seems contradictory and could point to an activating function of Mig1 or to activating zinc finger proteins that bear resemblance to Mig1. One assumption of Mig1 mediating glucose induction could be consistent with the finding that the fusion protein LexA-Mig1 (and also LexA-Mig2) activated transcription of a lexA operator-controlled reporter gene when the SSN6 gene was absent (Treitel \& Carlson, 1995; Lutfiyya \& Johnston, 1996). A second assumption is that of effectors that outcrowd Mig1 from its binding site, as supported by the existence of Msn2 and Msn4 (Lundin et al., 1994; Martínez-Pastor et al., 1996); MSN2 overexpression resulted in an occupation of Mig1-binding sites leading to an increased invertase expression (Schmitt \& McEntee, 1996). A third reconciling hypothesis, as in the case of $H X T 3$, could be that a weak Mig1-mediated repression counteracts general glucose induction, thus functioning as a fine-tuning controller of gene expression. This hypothesis fits in well with the finding of HXT2 and HXT4 transcription repression, which is mediated by Rgt 1 when no glucose is present and by Mig1 at high glucose concentrations (Özcan \& Johnston, 1996; Özcan et al., 1996). Concerning the phosphorylation step that follows sugar uptake, one may also speculate about the indirect effect Mig1 has via the control of $H X K 1$ and GLK1 expression on cell physiology.

From a holistic point of view it makes sense that the essential central metabolism of an organism stands under a more rigid control and exhibits a more complex control network than is the case for non-essential peripheral functions. Consequently, metabolic engineering of central functions is likely to be a greater challenge than that of peripheral ones. As to peripheral functions, success has already been achieved in partially derepressing galactose, maltose and sucrose metabolisms (Nehlin et al., 1991; Hu et al., 1995; Klein et al., 1996; Olsson et al., 1997). For central functions, industrial interest could, for example, lie in the creation of strains that exhibit higher specific growth rates for baker's yeast or recombinant protein production, or of distiller's yeast strains that give higher ethanol yields.

\section{REFERENCES}

Bell, W., Klaassen, P., Ohnacker, M., Boller, T., Herweijer, M., Schoppink, P., van der Zee, P. \& Wiemken, A. (1992). Characterization of the $56-\mathrm{kDa}$ subunit of yeast trehalose-6-phosphate synthase and cloning of its gene reveal its identity with the product of CIF1, a regulator of carbon catabolite inactivation. Eur J Biochem 209, 951-959.
Blom, J., Teixeira de Mattos, J. M. \& Grivell, L. A. (1997). Carbonsource control of respiratory function in Saccharomyces cerevisiae. In European Research Conferences: Control of Metabolic Flux, Approaches for Understanding the Control of Flux in Yeasts and Fungi, Giens, France, 14-18 June 1997 (programme and abstracts), p. 27.

Busturia, A. \& Lagunas, R. (1986). Catabolite inactivation of the glucose transport system in Saccharomyces cerevisiae. J Gen Microbiol 132, 379-385.

Caponigro, G. \& Parker, R. (1996). Mechanisms and control of mRNA turnover in Saccharomyces cerevisiae. Microbiol Rev 60, 233-249.

Cassart, J.-P., Georis, I., Östling, J., Ronne, H. \& Vandenhaute, J. (1995). The MIG1 repressor from Kluyveromyces lactis: cloning, sequencing and functional analysis in Saccharomyces cerevisiae. FEBS Lett 371, 191-194.

Celenza, J. L., Marshall-Carlson, L. \& Carlson, M. (1988). The yeast SNF3 gene encodes a glucose transporter homologous to the mammalian protein. Proc Natl Acad Sci USA 85, 2130-2134.

Cereghino, G. P. \& Scheffler, I. E. (1996). Genetic analysis of glucose regulation in Saccharomyces cerevisiae: control of transcription versus mRNA turnover. EMBO J 15, 363-374.

Crawford, M. J., Sherman, D. R. \& Goldberg, D. E. (1995). Regulation of Saccharomyces cerevisiae flavohemoglobin gene expression. J Biol Chem 270, 6991-6996.

Deckert, J., Perini, R., Balasubramanian, B. \& Zitomer, R. S. (1995). Multiple elements and auto-repression regulate Rox1, a repressor of hypoxic genes in Saccharomyces cerevisiae. Genetics 139, 1149-1158.

DeJuan, C. \& Lagunas, R. (1986). Inactivation of the galactose transport system in Saccharomyces cerevisiae. FEBS Lett 207, 258-261.

de Deken, R. H. (1966). The Crabtree effect: a regulatory system in yeast. J Gen Microbiol 44, 149-156.

DeVit, M. \& Johnston, M. (1996). Analysis of the regulation of the Mig1 glucose repressor. In Yeast Genetics and Molecular Biology, Madison, WI, USA, 6-11 August 1996 (programme and abstracts), p. 282.

Dowzer, C. E. A. \& Kelly, J. M. (1991). Analysis of the creA gene, a regulator of carbon catabolite repression in Aspergillus nidulans. Mol Cell Biol 11, 5701-5709.

Entian, K.-D. \& Barnett, J.A. (1992). Regulation of sugar utilization by Saccharomyces cerevisiae. Trends Biochem Sci 17, 506-510.

Entian, K.-D. \& Schuller, H.-J. (1997). Glucose repression (carbon catabolite repression) in yeast. In Yeast Sugar Metabolism, pp. 409-434. Edited by F. K. Zimmermann \& K.-D. Entian. Lancester, Basel: Technomic.

Federoff, H. J., Ecclesall, T.R. \& Marmur, J. (1983). Carbon catabolite repression of maltase synthesis in Saccharomyces cerevisiae. J Bacteriol 156, 301-307.

Fiechter, A., Fuhrmann, G. F. \& Kăppeli, O. (1981). Regulation of glucose metabolism in growing yeast cells. Adv Microb Physiol 22, 123-183.

Forsburg, S. L. \& Guarente, L. (1989). Identification and characterization of HAP4: a third component of the CCAAT-bound HAP2/HAP3 heteromer. Genes Dev 3, 1166-1178.

François, J., Neves, M.-J. \& Hers, H.-G. (1991). The control of trehalose biosynthesis in Saccharomyces cerevisiae: evidence for a catabolite inactivation and repression of trehalose-6-phosphate synthase and trehalose-6-phosphate phosphatase. Yeast 7, 575-587. 
Frederick, D. L. \& Tatchell, K. (1996). The REG2 gene of Saccharomyces cerevisiae encodes a type 1 protein phosphatasebinding protein that functions with Reg1p and the Snf1 protein kinase to regulate growth. Mol Cell Biol 16, 2922-2931.

Fu, L., Bounelis, P., Dey, N., Browne, B. L., Marchase, R. B. \& Bedwell, D. M. (1995). The posttranslational modification of phosphoglucomutase is regulated by galactose induction and glucose repression in Saccharomyces cerevisiae. J Bacteriol 177, 3087-3094.

Gallie, D. R. (1996). The cap and poly(A) tail function synergistically to regulate mRNA translational efficiency. Genes Dev 5 , 2108-2116.

Gancedo, J. M. (1992). Carbon catabolite repression in yeast. Eur J Biochem 206, 297-313.

Gancedo, C. \& Serrano, R. (1989). Energy-yielding metabolism. In The Yeasts, vol. 3, pp. 205-259. Edited by A. H. Rose \& J. S. Harrison. New York: Academic Press.

González, M. I., Stucka, R., Blázquez, M. A., Feldmann, H. \& Gancedo, C. (1992). Molecular cloning of CIF1, a yeast gene necessary for growth on glucose. Yeast 8, 183-192.

Gorts, C. P. M. (1969). Effect of glucose on the activity and the kinetics of the maltose-uptake system and of $\alpha$-glucosidase in Saccharomyces cerevisiae. Biochim Biophys Acta 184, 299-305.

Hardie, D. G. \& Carling, D. (1997). The AMP-activated protein kinase. Fuel gauge of the mammalian cell? Eur J Biochem 246, 259-273.

Hedges, D., Proft, M. \& Entian, K.-D. (1995). CAT8, a new zinc cluster-encoding gene necessary for derepression of gluconeogenic enzymes in the yeast Saccharomyces cerevisiae. Mol Cell Biol 15, 1915-1922.

Herrero, P., Galíndez, J., Ruiz, N., Martínez-Campa, C. \& Moreno, F. (1995). Transcriptional regulation of the Saccharomyces cerevisiae HXK1, HXK2 and GLK1 genes. Yeast 11, 137-144.

Hodge, M. R., Singh, K. \& Cumsky, M. G. (1990). Upstream activation and repression elements control transcription of the yeast COX5b gene. Mol Cell Biol 10, 5510-5520.

Hohmann, S. (1991). Characterization of PDC6, a third structural gene for pyruvate decarboxylase in Saccharomyces cerevisiae. J Bacteriol 173, 7963-7969.

Hohmann, S. (1993). Characterisation of PDC2, a gene necessary for high level expression of pyruvate decarboxylase structural genes in Saccharomyces cerevisiae. Mol Gen Genet 241, 657-666.

Hohmann, S., Huse, K., Valentin, E., Mbonyi, K., Thevelein, J. M. \& Zimmermann, F. K. (1992). Glucose-induced regulatory defects in the Saccharomyces cerevisiae byp1 growth initiation mutant and identification of MIG1 as a partial suppressor. J Bacteriol 174, 4183-4188.

Holzer, H. (1976). Catabolite inactivation in yeast. Trends Biochem Sci 1, 178-181.

Horak, J. \& Wolf, D. H. (1997). Catabolite inactivation of the galactose transporter in the yeast Saccharomyces cerevisiae: ubiquitination, endocytosis, and degradation in the vacuole. J Bacteriol 179, 1541-1549.

Hu, Z., Nehlin, J. O., Ronne, H. \& Michels, C. A. (1995). MIG1dependent and MIG1-independent glucose regulation of $M A L$ gene expression in Saccharomyces cerevisiae. Curr Genet 28, 258-266.

Jiang, R. \& Carlson, M. (1996). Glucose regulates protein interactions within the yeast SNF1 protein kinase complex. Genes Dev 10, 3105-3115.

Johnston, M. (1987). A model fungal gene regulatory mechanism: the GAL genes of Saccharomyces cerevisiae. Microbiol Rev 51, 458-476.

Johnston, M. \& Carlson, M. (1992). Regulation of carbon and phosphate utilization. In The Molecular and Cellular Biology of the Yeast Saccharomyces, pp. 193-281. Edited by E. W. Jones, J. R. Pringle \& J. R. Broach. Cold Spring Harbor, NY: Cold Spring Harbor Laboratory.

Kăppeli, O. (1986). Regulation of carbon metabolism in Saccharomyces cerevisiae and related yeasts. Adv Microbiol Pbysiol 28, 181-209.

Keleher, C. A., Redd, M. J., Schultz, J., Carlson, M. \& Johnson, A. D. (1992). Ssn6-Tup1 is a general repressor of transcription in yeast. Cell 68, 709-719.

Klein, C. J. L., Olsson, L., Rønnow, B., Mikkelsen, J. D. \& Nielsen, J. (1996). Alleviation of glucose repression of maltose metabolism by MIG1 disruption in Saccharomyces cerevisiae. Appl Environ Microbiol 62, 4441-4449.

Ko, C. H., Liang, H. \& Gaber, R. F. (1993). Roles of multiple glucose transporters in Saccharomyces cerevisiae. Mol Cell Biol 13, 638-648.

Kopp, M., Muller, H. \& Holzer, H. (1993). Molecular analysis of the neutral trehalase gene from Saccharomyces cerevisiae. J Biol Chem 268, 4766-4774.

Kratzer, S. \& Schuller, H.-J. (1997). Transcriptional control of the yeast acetyl-CoA synthetase gene ACS1 by the activators CAT8 and $A D R 1$ and the repressor UME6. Yeast 13 (Special issue), $S 98$.

Kruckeberg, A. L. (1996). The hexose transporter family of Saccharomyces cerevisiae. Arch Microbiol 166, 283-292.

Lazo, P. S., Ochoa, A. G. \& Gascón, S. (1978). $\alpha$-Galactosidase (melibiase) from Saccharomyces carlsbergensis: structural and kinetic properties. Arch Biochem Biophys 191, 316-324.

Liang, H. \& Gaber, R. F. (1996). A novel signal transduction pathway in Saccharomyces cerevisiae defined by Snf3-regulated expression of HXT6. Mol Biol Cell 7, 1953-1966.

Lohr, D., Venkov, P. \& Zlatanova, J. (1995). Transcriptional regulation in the yeast $G A L$ gene family: a complex genetic network. FASEB J 9, 777-787.

Lombardo, A., Cereghino, G. P. \& Scheffler, I. E. (1992). Control of mRNA turnover as a mechanism of glucose repression in Saccharomyces cerevisiae. Mol Cell Biol 12, 2941-2948.

Lundin, M., Nehlin, J. O. \& Ronne, H. (1994). Importance of a flanking AT-rich region in target site recognition by the GC boxbinding zinc finger protein MIG1. Mol Cell Biol 14, 1979-1985.

Lutfiyya, L. L. \& Johnston, M. (1996). Two zinc-finger-containing repressors are responsible for glucose repression of SUC2 expression. Mol Cell Biol 16, 4790-4797.

Luyten, K., Albertyn, J., Skibbe, W. F., Prior, B. A., Ramos, J., Thevelein, J. M. \& Hohmann, S. (1995). Fps1, a yeast member of the MIP family of channel proteins, is a facilitator for glycerol uptake and efflux and is inactive under osmotic stress. EMBO J 14, 1360-1371.

Maarse, A. C., de Haan, M., Bout, A. \& Grivell, L. A. (1988). Demarcation of a sequence involved in mediating catabolite repression of a gene for the $11 \mathrm{kDa}$ subunit VIII of ubiquinolcytochrome c oxidoreductase in Saccharomyces cerevisiae. Nucleic Acids Res 16, 5797-5811.

Martínez-Pastor, M. T., Marchler, G., Schuller, C., Marchler-Bauer, A., Ruis, H. \& Estruch, F. (1996). The Saccharomyces cerevisiae zinc finger proteins $M s n 2 p$ and Msn4p are required for transcriptional induction through the stress response element (STRE). EMBO J 15, 2227-2235. 
Mercado, J. J. \& Gancedo, J. M. (1992). Regulatory regions in the yeast FBP1 and PCK1 genes. FEBS Lett 311, 110-114.

Mercado, J. J., Vincent, O. \& Gancedo, J. M. (1991). Regions in the promoter of the yeast $F B P 1$ gene implicated in catabolite repression may bind the product of the regulatory gene MIG1. FEBS Lett 291, 97-100.

Mercado, J. J., Smith, R., Sagliocco, F. A., Brown, A. J. P. \& Gancedo, J. M. (1994). The levels of yeast gluconeogenic mRNAs respond to environmental factors. Eur J Biochem 224, 473-481.

Mwesigye, P. K. \& Barford, J. P. (1996). Mechanism of sucrose utilization by Saccharomyces cerevisiae. J Gen Appl Microbiol 42, 297-306.

Mylin, L. M., Johnston, M. \& Hoper, J. E. (1990). Phosphorylated forms of GAL4 are correlated with ability to activate transcription. Mol Cell Biol 10, 4623-4629.

Naumov, G. I., Naumova, E. S., Turakainen, H. \& Korhola, M. (1996). Identification of the $\alpha$-galactosidase $M E L$ genes in some populations of Saccharomyces cerevisiae: a new gene MEL11. Genet Res 67, 101-108.

Nehlin, J. O. \& Ronne, H. (1990). Yeast MIG1 repressor is related to the mammalian early growth response and Wilms' tumour finger proteins. EMBO J 9, 2891-2898.

Nehlin, J. O., Carlberg, M. \& Ronne, H. (1991). Control of yeast GAL genes by MIG1 repressor: a transcriptional cascade in the glucose response. EMBO J 10, 3373-3377.

Neigeborn, L. \& Carlson, M. (1987). Mutations causing constitutive invertase synthesis in yeast: genetic interactions with snf mutations. Genetics 115, 247-253.

Nwaka, S., Kopp, M. \& Holzer, H. (1995). Expression and function of the trehalase genes NTH1 and YBR0106 in Saccharomyces cerevisiae. J Biol Chem 270, 10193-10198.

Oechsner, U., Hermann, H., Zollner, A., Haid, A. \& Bandlow, W. (1992). Expression of yeast cytochrome $\mathrm{c} 1$ is controlled at the transcriptional level by glucose, oxygen and haem. Mol Gen Genet 232, 447-459.

Oh, D. \& Hopper, J. E. (1990). Transcription of a yeast phosphoglucomutase isozyme gene is galactose inducible and glucose repressible. Mol Cell Biol 10, 1415-1422.

Olsson, L., Larsen, M. E., Rønnow, B., Mikkelsen, J. D. \& Nielsen, J. (1997). Silencing MIG1 in Saccharomyces cerevisiae: effects of antisense MIG1 expression and MIG1 gene disruption. Appl Environ Microbiol 63, 2366-2371.

Östling, J., Carlberg, M. \& Ronne, H. (1996). Functional domains in the Mig1 repressor. Mol Cell Biol 16, 753-761.

Özcan, S. \& Johnston, M. (1995). Three different regulatory mechanisms enable yeast hexose transporter $(H X T)$ genes to be induced by different levels of glucose. Mol Cell Biol 15, 1564-1572.

Özcan, S. \& Johnston, M. (1996). Two different repressors collaborate to restrict expression of the yeast glucose transporter genes HXT2 and HXT4 to low levels of glucose. Mol Cell Biol 16, $5536-5545$.

Özcan, S., Leong, T. \& Johnston, M. (1996). Rgt1p of Saccharomyces cerevisiae, a key regulator of glucose-induced genes, is both an activator and a repressor of transcription. Mol Cell Biol $16,6419-6426$.

Özcan, S., Vallier, L. G., Flick, J. S., Carlson, M. \& Johnston, M. (1997). Expression of the SUC2 gene of Saccharomyces cerevisiae is induced by low levels of glucose. Yeast 13, 127-137.

Panek, A. D. (1991). Storage carbohydrates. In The Yeasts, vol. 4, pp. 655-677. Edited by A. H. Rose \& J. S. Harrison. New York: Academic Press.
Parets Soler, A., Casanova, M., Gozalbo, D. \& Sentandreu, R. (1987). Differential translational efficiency of the mRNAs isolated from derepressed and glucose repressed Saccharomyces cerevisiae. J Gen Microbiol 133, 1471-1480.

Petit, T. \& François, J. (1994). Accumulation of trehalose in Saccharomyces cerevisiae growing on maltose is dependent on the TPS1 gene encoding the UDPglucose-linked trehalose synthase. FEBS Lett 355, 309-313.

Pinkham, J. L. \& Guarente, L. (1985). Cloning and molecular analysis of the HAP2 locus: a global regulator of respiratory genes in Saccharomyces cerevisiae. Mol Cell Biol 5, 3410-3416.

Post-Beittenmiller, M. A., Hamilton, R. W. \& Hopper, J. E. (1984). Regulation of basal and induced levels of the MEL1 transcript in Saccharomyces cerevisiae. Mol Cell Biol 4, 1238-1245.

Randez-Gil, F., Bojunga, N., Proft, M. \& Entian, K. D. (1997). Glucose derepression of gluconeogenic enzymes in Saccharomyces cerevisiae correlates with phosphorylation of the gene activator Cat8p. Mol Cell Biol 17, 2502-2510.

Reifenberger, E., Freidel, K. \& Ciriacy, M. (1995). Identification of novel HXT genes in Saccharomyces cerevisiae reveals the impact of individual hexose transporters on glycolytic flux. Mol Microbiol 16, 157-167.

Riballo, E., Herweijer, M., Wolf, D. H. \& Lagunas, R. (1995). Catabolite inactivation of the yeast maltose transporter occurs in the vacuole after internalization by endocytosis. J Bacteriol 177, $5622-5627$

Ronne, H. (1995). Glucose repression in fungi. Trends Genet 11, 12-17.

Rosenkrantz, M., Kell, C. S., Pennell, E. A. \& Devenish, L. J. (1994). The HAP2,3,4 transcriptional activator is required for derepression of the yeast citrate synthase gene, CIT1. Mol Microbiol 13, 119-131.

Sadowski, I., Costa, C. \& Dhanawansa, R. (1996). Phosphorylation of Gal4p at a single C-terminal residue is necessary for galactoseinducible transcription. Mol Cell Biol 16, 4879-4887.

Santos, E., Rodríguez, L., Elorza, M. V. \& Sentandreu, R. (1982). Uptake of sucrose by Saccharomyces cerevisiae. Arch Biochem Biophys 216, 652-660.

Sanz, P., Nieto, A. \& Prieto, J. A. (1996). Glucose repression may involve processes with different sugar kinase requirements. J Bacteriol 178, 4721-4723.

Schlaepfer, I. R., Mattoon, J. R. \& Bajszár, G. (1994). The sequence and potential regulatory elements of the HEM2 promoter of Saccharomyces cerevisiae. Yeast 10, 227-229.

Schmitt, A. P. \& McEntee, K. (1996). Msn2p, a zinc finger DNAbinding protein, is the transcriptional activator of the multistress response in Saccharomyces cerevisiae. Proc Natl Acad Sci USA 93, 5777-5782.

Schmitt, H. D., Ciriacy, M. \& Zimmermann, F. K. (1983). The synthesis of yeast pyruvate decarboxylase is regulated by large variations in the messenger RNA level. Mol Gen Genet 192, 247-252.

Schork, S. M., Bee, G., Thumm, M. \& Wolf, D. H. (1994). Catabolite inactivation of fructose-1,6-bisphosphatase in yeast is mediated by the proteasome. FEBS Lett 349, 270-274.

Schöler, A. \& Schüller, H.-J. (1993). Structure and regulation of the isocitrate lyase gene ICL1 from the yeast Saccharomyces cerevisiae. Curr Genet 23, 375-381.

Schüller, H.-J. \& Entian, K.-D. (1991). Extragenic suppressors of yeast glucose derepression mutants leading to constitutive synthesis of several glucose-repressible enzymes. J Bacteriol 173, 2045-2052. 
Sierkstra, L. N., Nouwen, N. P., Verbakel, J. M. A. \& Verrips, C. T. (1992). Analysis of glucose repression in Saccharomyces cerevisiae by pulsing glucose to a galactose-limited continuous culture. Yeast 8, 1077-1087.

Siro, M.-R. \& Lövgren, T. (1978). On the properties of $\alpha$-glucosidase and the binding of glucose to the enzyme. Acta Chem Scand Ser B Org Chem Biochem 32, 447-451.

Sumner-Smith, M., Bozzato, R. P., Skipper, N., Davies, R. W. \& Hopper, J. E. (1985). Analysis of the inducible MEL1 gene of Saccharomyces carlsbergensis and its secreted product, $\alpha$-galactosidase (melibiase). Gene 36, 333-340.

Thevelein, J. M. (1994). Signal transduction in yeast. Yeast 10, 1753-1790.

Thevelein, J. M. \& Hohmann, S. (1995). Trehalose synthase: guard to the gate of glycolysis in yeast? Trends Biochem Sci 20, 3-10.

Treitel, M. A. \& Carlson, M. (1995). Repression by SSN6-TUP1 is directed by MIG1, a repressor/activator protein. Proc Natl Acad Sci USA 92, 3132-3136.

Trumbly, R. J. (1992). Glucose repression in the yeast Saccharomyces cerevisiae. Mol Microbiol 6, 15-21.

Tu, J. \& Carlson, M. (1995). REG1 binds to protein phosphatase type 1 and regulates glucose repression in Saccharomyces cerevisiae. EMBO J 14, 5939-5946.

Vallier, G. V. \& Carlson, M. (1994). Synergistic release from glucose repression by mig1 and ssn mutations in Saccharomyces cerevisiae. Genetics 137, 49-54.

Walsh, M. C., Scholte, M., Valkier, J., Smits, H. P. \& van Dam, K. (1996). Glucose sensing and signalling properties in Saccharomyces cerevisiae require the presence of at least two members of the glucose transporter family. J Bacteriol 178, 2593-2597.
Wanke, V., Vavassori, M., Thevelein, J. M., Tortora, P. \& Vanoni, M. (1997). Regulation of maltose utilization in Saccharomyces cerevisiae by genes of the RAS/protein kinase A pathway. FEBS Lett 402, 251-255.

Wendell, D. L. \& Bisson, L. F. (1994). Expression of high-affinity glucose transport protein Hxt2p of Saccharomyces cerevisiae is both repressed and induced by glucose and appears to be regulated posttranslationally. J Bacteriol 176, 3730-3737.

Wilson, W. A., Hawley, S. A. \& Hardie, D. G. (1996). Glucose repression/derepression in budding yeast : SNF1 protein kinase is activated by phosphorylation under derepressing conditions, and this correlates with a high AMP:ATP ratio. Curr Biol 6, 1426-1434.

de Winde, J. H. \& Grivell, L. A. (1993). Global regulation of mitochondrial biogenesis in Saccharomyces cerevisiae. Progr Nucleic Acid Res Mol Biol 46, 51-91.

de Winde, J. H., Crauwels, M., Hohmann, S., Thevelein, J. M. \& Winderickx, J. (1996). Differential requirement of the yeast sugar kinases for sugar sensing in establishing the catabolite-repressed state. Eur J Biochem 241, 633-643.

Yano, K.-i. \& Fukasawa, T. (1997). Galactose-dependent reversible interaction of Gal3p with Gal80p in the induction pathway of Gal4p-activated genes of Saccharomyces cerevisiae. Proc Natl Acad Sci USA 94, 1721-1726.

Yin, Z., Smith, R. J. \& Brown, A. J. P. (1996). Multiple signalling pathways trigger the exquisite sensitivity of yeast gluconeogenic mRNAs to glucose. Mol Microbiol 20, 751-764.

Zenke, F. T., Engels, R., Vollenbroich, V., Meyer, J., Hollenberg, C. P. \& Breunig, K. D. (1996). Activation of Gal4p by galactosedependent interaction of galactokinase and Gal80p. Science 272, $1662-1665$. 